\title{
O trabalho do agente comunitário na promoção da saúde: revisão integrativa da literatura
}

\author{
The work of community health agents in health promotion: an integrative literature review \\ El trabajo de agentes comunitarios en la promoción de salud: revisión integrativa de la literatura
}

\author{
Iara Cristina Pereira', Maria Amélia de Campos Oliveira" \\ ' Universidade Federal de Mato Grosso do Sul, Centro de Ciências Biológicas e da Saúde, \\ Departamento de Enfermagem. Campo Grande-MS, Brasil. \\ "Universidade de São Paulo, Escola de Enfermagem, Departamento de Enfermagem em Saúde Coletiva. \\ Programa de Pós-Graduação em Enfermagem, . São Paulo-SP, Brasil.
}

Submissão: 09-12-2012 Aprovação: 15-05-2013

\begin{abstract}
RESUMO
O presente artigo é uma revisão integrativa que teve como objetivo avaliar as evidências disponíveis na literatura sobre o desenvolvimento de estratégias operacionalizadas pelos agentes comunitários de saúde em prol da promoção da saúde. Para a seleção dos estudos foram usadas três bases de dados: BDTD, LILACS e SciELO. Foram encontradas 2.179 publicações, das quais 58 foram selecionadas para análise. Os resultados foram sistematizados em três categorias empíricas: A promoção da saúde: desafios na reorientação do modelo assistencial, A prática educativa no cotidiano de trabalho dos ACS e A formação profissional na perspectiva da Atenção Primária em Saúde. Concluiu-se que a construção de um modelo assistencial baseado na promoção da saúde requer a incorporação de novas práticas formativas, assistenciais e institucionais.
\end{abstract}

Descritores: Agentes Comunitários de Saúde; Promoção da Saúde; Atenção Primária em Saúde.

\begin{abstract}
This article is an integrative review that aimed to evaluate the available evidence in the literature on the development of strategies operationalized by community health agents for health promotion. Three databases were used - BDTD, LILACS and SciELO - and 2,179 publications were found, of which 58 were selected for analysis. The results were summarized in three empirical categories: Health promotion: challenges in reorienting the health care model, Educational practice in the daily work of community health agents and Vocational training in the perspective of Primary Health Care. The conclusion is that the construction of a model of care based on health promotion requires the incorporation of new educational, care-related and institutional practices.

Key words: Community Health; Health Promotion; Primary Health Care.

\section{RESUMEN}

Este artículo es una revisión integradora destinada a evaluar la evidencia disponible en la literatura sobre el desarrollo de las estrategias de operación de los agentes de salud comunitarios para la promoción de la salud. Para la selección de los estudios se utilizaron tres bases de datos: BDTD, LILACS y SciELO. Se encontraron 2.179 publicaciones, de las cuales 58 fueron seleccionados para análisis. Los resultados se resumen en tres categorías empíricas: Promoción de la salud: desafíos en la reorientación del modelo de atención de salud, Formación profesional en la perspectiva de la Atención Primaria de Salud y La práctica educativa en el trabajo diario de ACS. Se concluyó que la construcción de un modelo de atención basado en la promoción de la salud requiere la incorporación de nuevas prácticas de formación, de asistencia e institucionales.
\end{abstract}

Palabras clave: Salud Comunitaria; Promoción de la Salud; Atención Primaria de Salud. 


\section{INTRODUÇÃO}

O conceito de determinação social da saúde ocupa lugar de destaque entre as formulações doutrinárias que orientaram o movimento sanitário brasileiro desde suas origens na década de 1970. Tal conceito está assentado sobre a premissa de que a saúde humana deve ser compreendida e analisada a partir das formas de organização da sociedade, ou seja, de sua estrutura econômica e social, na medida em que esta dimensão subordina ou subsume as dimensões naturais atinentes ao ambiente físico e à constituição genética e fisiológica dos indivíduos.

A Constituição Brasileira de 1988, na seção II (Sobre a saúde), artigo 196, reconheceu a saúde como "direito de todos e dever do Estado, garantido mediante políticas sociais e econômicas que visem à redução do risco de doença e de outros agravos e ao acesso universal e igualitário às ações e serviços para a promoção, proteção e recuperação"(1). Posteriormente, a Lei 8.080/90, no artigo $3^{\circ}$, fez menção aos determinantes e condicionantes da saúde, entre os quais a alimentação, a moradia, o saneamento básico, o meio ambiente, o trabalho, a renda, a educação, o transporte, o lazer e o acesso aos bens e serviços essenciais ${ }^{(2)}$.

O atual conceito de saúde procura resgatar a importância das dimensões econômica, social e política na produção da saúde e da doença nas coletividades. Contrapõe-se à concepção biomédica, baseada no conhecimento anatomopatológico e na abordagem mecanicista do corpo, cujo modelo assistencial está centrado no indivíduo, na doença, no hospital e no profissional médico.

Entretanto, a visão ampliada, positiva e complexa de saúde reveste-se de desafios para a prática cotidiana dos profissionais, sendo necessário dar concretude e expressão a esse novo conceito nos serviços de saúde. Nesse sentido, as práticas de promoção da saúde têm representado uma possibilidade concreta de ruptura do paradigma biomédico ao proporem uma nova forma de intervenção no campo da saúde.

A promoção de saúde pressupõe uma concepção que não restrinja a saúde à ausência de doença, mas que seja capaz de atuar sobre seus determinantes e condicionantes. Modelos de atenção dela derivados buscam atuar sobre as condições de vida da população, extrapolando a prestação de serviços clínico-assistenciais e requerendo ações intersetoriais que envolvam a educação, o saneamento básico, a habitação, a renda, o trabaIho, a alimentação, o meio ambiente, o lazer e o acesso a bens e serviços essenciais, entre outros condicionantes da saúde.

Considerada um dos eixos estruturantes do Sistema Único de Saúde (SUS) brasileiro, a promoção da saúde envolve cinco áreas de atuação: elaboração e implementação de políticas públicas saudáveis, criação de ambientes favoráveis à saúde, reforço da ação comunitária, desenvolvimento de habilidades pessoais e reorientação dos sistemas e dos serviços de saúde ${ }^{(3-4)}$.

Em termos operacionais, a Estratégia Saúde da Família (ESF) é considerada uma alternativa para a reorientação do modelo de atenção, com ênfase na promoção da saúde. Ao centrar a atenção na família em um contexto físico e social particular, deve atuar mediante ama compreensão ampliada do processo saúde-doença, reconhecendo a necessidade de intervenções para além das práticas curativas.
Na ESF, a equipe multidisciplinar mínima é composta por um médico generalista ou médico da família, um enfermeiro, um auxiliar ou técnico de enfermagem e quatro a seis agentes comunitários de saúde (ACS). Por residirem na própria comunidade em que trabalham, os ACS conhecem profundamente as crenças, os valores, a linguagem, os perigos e as oportunidades da realidade em que vivem.

O documento do Ministério da Saúde intitulado Perfil de competências do agente comunitário de saúde cita as habilidades e conhecimentos necessários à atuação do ACS. Além de desenvolver integração da equipe com a população local, planejar e avaliar ações de saúde, prevenir e monitorar grupos específicos, morbidades e riscos ambientais e sanitários, o ACS deve realizar a promoção da saúde ${ }^{(5)}$.

Para tanto, deve buscar articular saberes técnicos e populares, mobilizar recursos institucionais e comunitários, públicos e privados, de diversos setores, para o enfrentamento dos problemas de saúde. Nessa perspectiva, a população assume um papel ativo no processo de construção das práticas sanitárias.

Diante desse contexto, julgou-se oportuno identificar as evidências disponíveis na literatura sobre o desenvolvimento de estratégias operacionalizadas pelo ACS em prol da qualidade de vida de pessoas e coletividades. Assim, realizou-se a presente investigação, cujo objetivo foi identificar no trabalho do ACS ações comprometidas com a promoção da saúde.

\section{MÉTODO}

Para o alcance dos objetivos propostos, optou-se pelo método da revisão integrativa, que possibilita sintetizar pesquisas já concluídas e obter resultados a partir de um tema de interesse $^{(6)}$. A revisão integrativa é definida como um método de avaliação crítica que agrupa resultados de estudos voltados a um mesmo tema ou objeto, com vistas a analisar e sintetizar dados para desenvolver uma explicação mais abrangente de um fenômeno específico ${ }^{(7)}$.

As etapas seguidas para a realização da pesquisa foram: formulação do problema, coleta, avaliação, análise e interpretação dos dados e apresentação dos resultados. Obedeceram recomendações sobre a objetividade, a didática e a clareza a serem cumpridas durante o desenvolvimento do estudo ${ }^{(7)}$.

Com relação à formulação do problema, a questão norteadora do estudo deve ser formulada de modo a evidenciar o propósito da pesquisa, com especial cuidado na definição dos critérios de inclusão e exclusão, bem como dos descritores a serem utilizados ${ }^{(7)}$. No presente estudo, a questão norteadora foi: "Que estratégias têm sido utilizadas pelo ACS para realizar ações comprometidas com a promoção da saúde?".

A seleção de estratégias de busca deve tentar minimizar a perda de estudos (ir além das bases de dados mais comuns e amplas, buscar pesquisas não publicadas, utilizar bases específicas e que podem ser mais direcionadoras) e objetivar a eficiência, ou seja, usar primeiramente as fontes que sejam mais propensas a trazer resultados ${ }^{(8)}$. Assim, na coleta de dados foram utilizadas estratégias de busca em bases de dados, observados os critérios de inclusão e exclusão dos estudos.

Os critérios de inclusão foram: artigos divulgados na íntegra 
em língua inglesa, portuguesa ou espanhola publicados em periódicos nacionais e internacionais após 1991, ano de proposição pelo Ministério da Saúde do Programa de Agentes Comunitários em Saúde (PACS); que possuam em seus descritores ou título termos como 'Agente Comunitário de Saúde', 'promoção da saúde', 'visita domiciliar', 'educação em saúde', 'participação comunitária' e 'Programa Saúde da Família' ou as seguintes palavras-chave: 'determinantes de saúde', 'Estratégia Saúde da Família' e 'conceito de saúde'; artigos com disponibilidade de resumos e com informações sobre objetivos e abordagens metodológicas; artigos que discutam a experiência de agentes comunitários do Brasil; dissertações e teses de doutorado.

Como critérios de exclusão foram considerados: documentos técnicos, resumos de congressos, anais, editoriais, comentários e opiniões e artigos de reflexão; artigos não encontrados na íntegra; artigos relativos à experiência de outros países que não o Brasil.

O levantamento bibliográfico foi realizado via internet em três bases de dados eletrônicas: LILACS (Literatura Latino-Americana e do Caribe em Ciências de Saúde, disponível em http://www.bireme.br), SciELO (Scientific Electronic Library Online, disponível em http://www.scielo.br) e BTDT (Biblioteca Digital de Teses e Dissertações, da Coordenação de Aperfeiçoamento de Pessoal de Nível Superior - Capes), disponível em http://btdt.ibict.br/btdt), que integra teses e dissertações provenientes de instituições de ensino superior brasileiras, permitindo acesso na íntegra.

A coleta foi realizada nos meses de junho e julho de 2012. Foram utilizadas várias estratégias de busca (combinação de palavras-chave e descritores em saúde). A princípio, havia intenção de selecionar publicações cujo objeto de estudo fosse apenas o ACS. Entretanto, foram identificados vários trabalhos sobre a ESF em que o ACS foi sujeito da pesquisa e que mencionavam aspectos importantes sobre o trabalho deste. Decidiu-se então apreciar também esses estudos, entendendo-se que o ACS integra a equipe de saúde na ESF e que suas atividades são reflexo da direcionalidade conferida ao processo de trabalho em saúde.

Para avaliação dos resultados, que configura a terceira etapa da revisão integrativa, foi elaborado um instrumento para sumarizar e documentar as informações sobre as publicações incluídas na revisão. O instrumento contemplou: ano de publicação, identificação da publicação original, autores, objetivos do estudo, características metodológicas do estudo, resultados encontrados, conclusões e recomendações dos autores.

\section{RESULTADOS}

A Tabela 1 mostra o número de publicações encontradas nas bases de dados no momento inicial da pesquisa e nas fases subsequentes, até a seleção final. A princípio, procedeu-se à leitura dos títulos e resumos dos 2.179 estudos. Nessa etapa foram excluídas 2.004 publicações que não respondiam às questões de pesquisa, que abordavam aspectos promocionais relativos a alguma doença ou transtorno ou que discutiam aspectos promocionais referentes a um grupo determinado da população.

Procedeu-se então à leitura na íntegra de 115 artigos pré-selecionados e também à releitura de resumos, resultados e considerações finais das 47 publicações, incluindo teses e dissertações. Foram então excluídos todos os estudos duplicados ou presentes em mais de uma base de dados, o que resultou em 58 publicações: 32 da base de dados BDTD, 18 da LILACS e oito da SciELO.

Tabela 1 - Número de estudos encontrados, excluídos, pré-selecionados e selecionados nas bases dados eletrônicas.

\begin{tabular}{lcccc}
\hline Número de estudos/Bases de dados & Encontrados & Excluídos & Pré-selecionados & Selecionados \\
\hline BDTD & 718 & 658 & 47 & 32 \\
LILACS & 397 & 352 & 45 & 70 \\
SciELO & 1.064 & 994 & 185 & 08 \\
\hline Total & 2.179 & 2.004 & 58 \\
\hline
\end{tabular}

Tabela 2 - Distribuição do total de publicações segundo tipo de estudo e ano de publicação. 2012. (N = 58).

\begin{tabular}{|c|c|c|c|c|}
\hline \multirow[b]{2}{*}{ Ano } & \multicolumn{4}{|c|}{ TIPO DE ESTUDO } \\
\hline & $\begin{array}{c}\text { Qualitativo } \\
(n)\end{array}$ & $\begin{array}{c}\text { Qualiquantitativo } \\
(n)\end{array}$ & $\begin{array}{c}\text { Quantitativo } \\
(n)\end{array}$ & Total \\
\hline 2004 & 1 & -- & -- & 1 \\
\hline 2005 & 5 & --- & -- & 5 \\
\hline 2006 & 3 & - & - & 3 \\
\hline 2007 & 4 & --- & 1 & 5 \\
\hline 2008 & 7 & 1 & 1 & 9 \\
\hline 2009 & 8 & 1 & -- & 9 \\
\hline 2010 & 13 & - & 1 & 14 \\
\hline 2011 & 9 & 3 & - & 12 \\
\hline Total & 50 & 5 & 3 & 58 \\
\hline
\end{tabular}


Para classificação dos estudos foi identificado o método de análise adotado. Quando a pesquisa recorreu a instrumentos estatísticos para analisar seus dados e responder à questão central, foi nomeada quantitativa. Métodos de análise que incluíram procedimentos assemelhados à análise de conteúdo ou temática foram intitulados qualitativos. A Tabela 2 evidencia que os estudos com abordagem qualitativa foram predominantes em $86,2 \%$ das publicações.

Quanto ao ano de publicação, constatou-se que os estudos sobre promoção da saúde têm aumentado ano a ano. Possivelmente a atualidade do tema está relacionada às mudanças no cenário científico nacional e também aos desafios da construção de um novo modelo assistencial.

Considerando apenas os artigos publicados, segundo o tipo de periódico, constatou-se que os 26 artigos encontrados foram publicados em 10 periódicos diferentes, seis dos quais continham uma única publicação sobre o tema da presente pesquisa (Tabela 3).

Os periódicos com maior número de publicações foram Revista Ciência \& Saúde Coletiva, com oito (30,77\% do total); Interface, Comunicação, Saúde e Educação, com quatro (15,38\%); Revista Brasileira Enfermagem e Revista de Atenção Primária em Saúde, cada uma com três $(11,54 \%)$; e Revista Saúde e Sociedade, com duas publicações (7,69\%). Os percentuais certamente estão relacionados ao tempo de existência do periódico, periodicidade de publicação, articulação com diferentes áreas do conhecimento e parcerias científicas, entre outros aspectos.

Tabela 3 - Distribuição dos artigos analisados, segundo periódicos de publicação - Lilacs e SciELO. $(\mathrm{N}=26)$.

\begin{tabular}{lcc}
\hline \multicolumn{1}{c}{ Periódico } & N & \% \\
\hline Rev. Ciência \& Saúde Coletiva & 8 & 30,77 \\
Interface Comunicação, Saúde, Educação & 4 & 15,38 \\
Rev. Bras. Enferm. & 3 & 11,54 \\
Rev. APS & 3 & 11,54 \\
Rev. Saúde Soc. & 2 & 7,69 \\
*Rev. Latino-am Enfermagem; & & \\
Physis Revista de Saúde Coletiva; & & 23,08 \\
Rev. enferm. UERJ; RBPS; Paideia; RAC eletrônica & & \\
\hline Total & 26 & 100,0 \\
\hline
\end{tabular}

*Periódicos com uma única publicação sobre o tema.

Dentre os estudos de pós-graduação (mestrado e doutorado), 14 eram de autoria de enfermeiros, três foram desenvolvidos por psicólogos, quatro distribuíram-se entre as profissões de serviço social, terapia ocupacional, veterinária e nutrição e 11 não informaram categoria profissional dos autores. A mesma tendência foi constatada nos artigos, em que foi verificada a autoria de enfermeiros em 27 estudos, seguida por profissionais de medicina (três), odontologia (dois), serviço social e psicologia (um cada). A falta de menção à categoria profissional dos autores chamou atenção pelo fato de não se identificar a profissão de 46 deles.

Quando analisada a instituição de origem dos responsáveis pelos artigos, verificou-se que $81,1 \%$ eram profissionais que trabalhavam em universidades e instituições federais ou estaduais ligadas ao ensino e pesquisa, 5,4\% eram estudantes de graduação e pós-graduação, 2,7\% eram trabalhadores de serviços públicos estaduais ou municipais, 2,7\% trabalhavam em serviços privados e 1,5\% representavam entidades internacionais. Em 6,75\% dos artigos não foi possível identificar a instituição de origem.

Com relação à instituição de defesa dos estudos de pós-graduação, constatou-se que $71,88 \%$ das universidades localizavam-se na região Sudeste. O estado de São Paulo respondeu por $43,75 \%$ das instituições, sendo que a Universidade de São Paulo foi a instituição de defesa de $34,5 \%$ das pesquisas. Às instituições localizadas nas regiões Sul, Centro-Oeste e Nordeste couberam percentuais de $12,5 \%, 9,37 \%$ e $6,25 \%$, respectivamente.

Os estudos analisados foram classificados em três categorias empíricas: 'A promoção da saúde: desafios na reorientação do modelo assistencial', 'A prática educativa no cotidiano de trabalho dos ACS' e 'A formação profissional na perspectiva da Atenção Primária em Saúde'. Essa classificação foi feita de forma mutuamente excludente. Entretanto, é importante dizer que a inclusão em uma categoria significa ênfase em determinado tema e não sua abordagem exclusiva.

A categoria 'A promoção da saúde: desafios na reorientação do modelo assistencial' reúne aspectos relativos à intersetorialidade, participação popular, trabalho em equipe, práticas de saúde e conceito de saúde, inerentes ao modelo assistencial proposto pelo SUS. Na categoria 'A prática educativa no cotidiano de trabalho dos ACS' são discutidos os métodos pedagógicos utilizados pelo ACS na mediação de saberes com a comunidade. Na última categoria, 'A formação profissional na perspectiva da Atenção Primária em Saúde', é debatida a necessidade de uma formação ampliada e contextualizada para atender à complexidade da realidade social.

\section{DISCUSSÃO}

Promover a saúde, como o próprio termo sugere, pressupõe favorecer seu desenvolvimento. Considerada uma proposta de política pública mundial, decorrência do amplo debate sobre a determinação social e econômica da saúde, a promoção da saúde é definida como ${ }^{(8)}$

[...] um processo político e social global que abarca não somente ações dirigidas diretamente a fortalecer habilidades e capacidades dos indivíduos, mas também a modificar condições sociais, ambientais e econômicas, com o objetivo de aliviar seu impacto na saúde pública e individual. A promoção da saúde é um processo que permite que as pessoas aumentem o controle sobre os determinantes da saúde e em consequência melhorem sua saúde. A participação é essencial para sustentar as ações de promoção da saúde.

Para isso, faz-se necessário romper a fragmentação na abordagem das doenças, o que requer uma nova forma para 
organizar e articular os diversos recursos físicos e tecnológicos disponíveis, assim como a força de trabalho, a fim de que se possam enfrentar e resolver os problemas de saúde de uma coletividade. Nesse sentido, a proposta da Política Nacional de Promoção da Saúde constitui um esforço para o enfrentamento dos desafios do modelo assistencial, num cenário sócio-histórico cada vez mais complexo e que exige qualificação contínua das práticas sanitárias e reflexão sobre elas.

A ESF é uma proposta para reorientação da atenção Básica e, por conseguinte, tem potencial para promover mudanças no modelo assistencial de saúde. Sua implementação requer profissionais que lidem com os determinantes sociais de saúde, articulando o trabalho de maneira intersetorial com a realidade local do território, e que sejam capazes de estabelecer relações de cuidado efetivas, baseadas no acolhimento.

Por meio do acolhimento é possível melhorar o acesso dos usuários aos serviços de saúde, mudando a forma tradicional de entrada, que se dá por meio de filas e por ordem de chegada. $\mathrm{O}$ acolhimento caracteriza-se também pelo desenvolvimento de relações de vínculo entre a equipe de saúde, a família e a coletividade, o que pressupõe abertura, valorização do outro e disponibilidade para a escuta, além do trabalho em equipe, que se concretiza na medida em que há articulação das ações e interação entre os profissionais de saúde.

O trabalho interdisciplinar amplia a capacidade de entendimento da complexidade e da diversidade do objeto do trabalho em saúde. Consiste, portanto, em uma prática social coletiva, democrática e participativa na qual são compartilhados objetivos, conhecimentos e experiências a fim de solucionar, de forma integral, problemas individuais e coletivos, que requerem muitas vezes ações de caráter intersetorial. Ou seja, embora os problemas sociais se manifestem no setor da saúde, sua solução está na dependência da ação de mais de uma política. São partes de um todo complexo, demandando-se uma maneira integrada para resolvê-los.

A concepção ampliada de saúde, para além da prevenção, assistência e recuperação dos enfermos, por um lado impõe respostas intersetoriais na esfera das reformas institucionais e, por outro, requer o envolvimento e responsabilização de distintos sujeitos, população e gestores nas políticas e ações de atenção à saúde ${ }^{(9)}$.

Para o desenvolvimento de uma cultura de trabalho intersetorial, a ESF necessita, entre outras coisas, conhecer os condicionantes da qualidade de vida da população, promover ações integradas e agenciar parcerias com organizações formais e informais existentes na sociedade para o enfrentamento conjunto dos problemas identificados.

Cabe destacar a importância da participação popular e a necessidade de um processo de construção social do direito à saúde. A participação social é uma estratégia de empoderamento pela oportunidade de educação para a cidadania, socialização de informações, envolvimento no diagnóstico e na tomada de decisões e execução dos projetos sociais, resultando no compartilhamento de responsabilidades na gestão da saúde.

A participação da coletividade na identificação dos problemas e necessidades em saúde, assim como no planejamento e avaliação das ações de saúde, reflete o processo de democratização das instituições, uma vez que se insere no microespaço das relações entre usuários, profissionais e conselheiros de saúde ${ }^{(10)}$.

A constituição de um novo modelo de saúde demanda um conjunto de mudanças assistenciais, gerenciais e intersetoriais, o que requer determinação, comprometimento e apoio político do gestor municipal para fortalecer um pacto social entre as autoridades locais, as organizações sociais e as instituições do setor público e privado.

Para que ocorram mudanças no setor de saúde, é essencial o estabelecimento de compromissos formais e a implementação de um plano de ação para o desenvolvimento sustentável do município, o que proporcionará melhoria das condições sociais a longo prazo, com meta de garantir saúde e qualidade de vida a seus habitantes.

Desenvolver políticas públicas com foco nos determinantes das condições de vida e saúde é o principal desafio para os gestores municipais, porque pressupõe romper com o modelo tradicional de administração pública - assistencialista, fragmentado e burocrático -, rumo a um novo modelo de gestão compartilhado com a sociedade. Isso exige percepção ampliada do conceito de saúde, capacidade de negociação e articulação e criação de mecanismos de participação democrática.

Com base em todos esses aspectos teóricos e conceituais que envolvem a construção de um modelo assistencial baseado na promoção da saúde, discutem-se a seguir os resultados dos estudos selecionados, mediante o diálogo com diversos autores.

\section{A. A promoção da saúde: desafios na reorientação do mo- delo assistencial}

Embora a intersetorialidade seja uma das estratégias para promoção da saúde, nos estudos analisados constatou-se que esta ainda não é uma vivência prática nos serviços e sistemas de saúde. Assim, ainda que os profissionais estejam preparados para identificar os determinantes sociais do processo saúde-doença, não se encontram capacitados para refletir e intervir sobre estes, e muito menos para identificar estratégias para a construção da intersetorialidade.

Esta realidade é decorrência da pouca compreensão em termos conceituais pelos profissionais de saúde, que muitas vezes confundem o termo com a interdisciplinaridade, além da lógica tradicional de gestão pública municipal, que se caracteriza por relações de poder e pelo trabalho fragmentado e setorializado.

De acordo com vários autores ${ }^{(11-13)}$, os profissionais de saúde encontram-se capturados e engessados pelos programas ministeriais, pelo cumprimento de metas pré- estabelecidas e pela eleição de prioridades em sua maioria distantes das reais necessidades da população. Isso dificulta iniciativas diferenciadas ou locais para o enfrentamento dos problemas de saúde.

A intersetorialidade demanda mudanças na organização, tanto dos sistemas como dos serviços de saúde. Também é necessária a valorização dos saberes técnicos envolvidos na formulação e implementação de políticas, com investimento em recursos humanos, conduzindo-os a uma atuação articulada ${ }^{(9)}$.

A participação social, considerada dimensão relevante para a promoção da saúde, cujo objetivo é a autonomia e a emancipação dos usuários, ainda é tímida ou inexistente, segundo 
os estudos analisados. Os limites no processo de participação estão relacionados à falta de capacitação e à ausência de uma cultura de participação, além do desconhecimento dos usuários com relação ao sistema sanitário e aos direitos sociais conquistados com a Constituição de 1988.

Considera-se que, as expectativas criadas pelo movimento da Reforma Sanitária em torno da participação da coletividade na deliberação sobre a política de saúde, não levaram em conta a força da cultura política tradicional que continua condicionando as práticas de participação, não só dentro dos conselhos de saúde, mas também nos espaços de movimentos sociais e comunitários ${ }^{(14)}$.

As recomendações registradas nos relatórios das cinco últimas Conferências Nacionais de Saúde ( $9^{\mathrm{a}}$ a $13^{\mathrm{a}}$ ), relativos ao tema controle social, reforçam as limitações referentes à falta de paridade, ao clientelismo e ao nepotismo na indicação de conselheiros e as práticas patrimonialistas no uso dos recursos públicos $^{(15)}$.

Apesar da existência de legislação específica que regulamenta e estimula a democratização do poder local, a participação social idealizada pela Reforma Sanitária brasileira, capaz de apropriar-se de canais de participação que possam influir diretamente na construção de políticas, ou de construí-los, permanece como desafio.

As relações interpessoais que se estabelecem entre usuários e trabalhadores podem ou não contribuir para aproximá-los dos espaços de participação social. O modelo biomédico, caracterizado pela cultura científica, pelo autoritarismo e pela verticalidade na comunicação, pode ser limitante para a construção de espaços participativos.

Os estudos selecionados para análise evidenciaram a predominância do modelo tradicional da biomedicina, centrado na doença e nos fatores biológicos. Consequentemente, a lógica do trabalho dos profissionais de saúde, incluindo o ACS, mantém-se centrada em ações que buscam sanar problemas relacionados a patologias ou alterações físicas. Assim, embora a saúde dos indivíduos e dos grupos seja tomada como objeto de trabalho, a família ainda é tratada segundo o modelo biológico, o que tem culminando no desenvolvimento de uma atenção focal e fragmentada.

A forma como os serviços organizam as relações e o processo de trabalho, o reconhecimento de quais são os problemas e as necessidades de saúde aos quais os profissionais e serviços devem responder e a identificação das práticas e saberes que devem ser utilizados nessa resposta são determinados pelos conceitos que os profissionais de saúde têm de saúde e doença ${ }^{(16)}$. Infere-se, portanto, que a visão médico-centrada é decorrência principalmente da formação dos profissionais, que, ao adotar determinada explicação para o adoecimento - com enfoque ainda predominantemente biologicista -, acaba delineando também a forma resolutiva (curativa) de atuação sobre os problemas do processo saúde-doença.

\section{B. A prática educativa no cotidiano de trabalho dos ACS}

Dentre as atividades desenvolvidas pelo ACS, a educação em saúde pode ser considerada como uma das pedras angulares da promoção em saúde. A educação é um instrumento fundamental na saúde quando se constitui em ação política que busca a participação popular como forma de garantir aos sujeitos a possibilidade de decidir seus próprios destinos (individuais e/ou coletivos), por meio de uma participação consciente (ação/reflexão/ação), na qual os sujeitos constroem sua própria trajetória histórica em busca de uma vida melhor ${ }^{(17)}$.

A educação tem como princípios a liberdade humana, o processo de emancipação e formação integral, a autonomia, a conscientização, a reflexão crítica sobre o mundo e a formação política dos sujeitos. Essa prática pedagógica ou construção coletiva do conhecimento está alicerçada no conceito de saúde como qualidade de vida, equidade, participação e cidadania, ancorada no conceito de educação como problematização da realidade, autoconhecimento e autotransformação. É intitulada Educação Popular em Saúde porque pressupõe que o saber popular, juntamente com o saber técnico, constrói o saber coletivo da saúde, resultante das condições de vida e trabalho.

Um dos elementos principais do trabalho do ACS é realizar a mediação entre esses saberes, já que se encontra imerso no conhecimento popular e, por outro lado, incorpora conhecimentos científicos ao integrar as equipes multiprofissionais. Em que medida, no entanto, consegue ser o elo entre o saber científico e o saber popular, possibilitando uma prática dialógica em educação em saúde?

Os estudos analisados mostraram que a visão de educação transformadora é pouco presente no cotidiano de trabalho dos ACS. Prevalecem a concepção de saúde como ausência de doença e a visão de que a educação em saúde consiste na transmissão de informações sobre prevenção e controle de doenças. Esse fazer profissional baseado em normas e conseIhos reflete a concepção tradicional da educação, na qual o educador é sujeito do processo educativo (ACS), sendo considerado detentor do saber, enquanto os educandos (usuários) são meros objetos nos quais são depositadas informações ${ }^{(10)}$.

Algumas consequências dessa pedagogia são a passividade e a falta de crítica, a distância entre teoria e prática e a falta de "problematização" da realidade, que repercutem tanto em nível individual como social. Entretanto, a adoção da pedagogia tradicional não é resultado somente de opções individuais dos ACS, mas está fundamentalmente relacionada às cobranças institucionais que privilegiam formas de mediação convencedoras e reprodutoras.

Assim, embora o ACS tenha potencial de atuação política e educativa, na maioria das vezes decorrente de percepções e opções individuais, não dispõe de respaldo da unidade básica de saúde (UBS) nessa dimensão de atuação ${ }^{(18)}$. Prevalecem as condutas técnicas estimuladas por objetivos propostos pela UBS a partir de metas quantitativas pré-estabelecidas pelas secretarias municipais de saúde, que elaboram prioridades que, em sua maioria, estão distantes das necessidades da população(11).

O potencial de atuação política e educativa do ACS denota a importância de reconhecer o saber, as vivências e as experiências que esse profissional traz acerca do processo saúde-doença e da dinâmica de vida e trabalho da coletividade em que vive. Todavia, esse saber não normatizado tem sido desvalorizado pelas equipes ou no contexto dos conhecimentos disciplinares que são oferecidos pelos cursos de capacitação. 
Acrescente-se ainda que, apesar do ACS evidenciar pontos sutis do processo de trabalho ou dos casos clínicos acompanhados, é silenciado ou silencia-se na equipe de saúde, pela dificuldade de trabalhar em equipe e de utilizar, no cotidiano das práticas, dados concernentes à subjetividade e ao modo de vida das pessoas ${ }^{(19)}$.

A inexistência ou deficiência de uma abordagem interdisciplinar e a parcialidade do atual modelo assistencial e das posturas pedagógicas utilizadas na educação em saúde remetem à necessidade imperiosa de mudanças na formação dos profissionais de saúde.

\section{A formação profissional na perspectiva da Atenção Pri-} mária em Saúde

A formação profissional dá-se para o trabalho e nele se completa. O processo formativo é inacabado, em constante transformação, para responder às complexidades e às mudanças dinâmicas da realidade social. Embora as atuais políticas de ensino para a área de saúde enfatizem a formação nos cenários reais dos serviços de saúde, especialmente a Atenção Básica, muitas instituições formadoras ainda continuam estruturadas segundo a lógica tradicional dos currículos fragmentados em inúmeras disciplinas desarticuladas, formando profissionais de saúde com uma visão predominantemente centrada em práticas fragmentadas e especializadas de atenção.

Modelos de saúde na perspectiva da Atenção Primária em Saúde requerem uma formação mais ampla e contextualizada, que possibilite perfis profissionais com capacidade de reconhecer contextos e mobilizar soluções criativas para situações complexas, com habilidade de comunicação e acolhimento, com capacidade de compreensão de diferentes valores e culturas e com aptidão para o trabalho em equipe.

A articulação de diferentes saberes e fazeres é uma ferramenta importante para lidar com a complexidade do processo de saúde, além de propiciar uma mudança na estrutura social da equipe, ainda muito baseada na centralidade do trabalho médico.

Os estudos que foram objeto desta revisão integrativa enfatizaram a relevância do diálogo entre os diferentes campos do conhecimento e a necessidade da prática multiprofissional com uma abordagem interdisciplinar e intersetorial para atuar efetivamente na promoção da saúde.

Interdisciplinaridade pressupõe um trabalho coordenado e com objetivo comum, partilhado por vários ramos do saber, de forma integrada e convergente. Diante desse contexto, a Educação Permanente em Saúde ${ }^{(20)}$, pode ser uma oportunidade de reflexão sobre a prática, contribuindo para a atualização técnico-científica e, sobretudo, para construção de uma atuação crítica, reflexiva, propositiva, compromissada e tecnicamente competente.

A gerência dos serviços e os gestores têm a responsabilidade institucional de interferir positivamente na motivação e na mobilização dos profissionais para uma atuação consoante com as premissas da ESF.

\section{CONSIDERAÇÕES FINAIS}

A construção de um modelo assistencial baseado na promoção da saúde não é dada a priori, mas construída no cotidiano das relações políticas entre sujeitos sociais. Demanda compromisso com a mudança e requer a incorporação de novas práticas formativas, assistenciais e institucionais.

Na dimensão formativa, é fundamental que o processo de formação dos profissionais de saúde seja orientado pela leitura das necessidades sociais em saúde, mediante o debate com os organismos de gestão e participação social do SUS. Para tanto, é necessário que os setores da educação e da saúde estabeleçam uma estreita e permanente parceria interinstitucional, objetivando desenvolver ações conjuntas e articuladas para a elaboração e a construção de uma proposta educacional que conjugue os conhecimentos produzidos e acumulados pelas duas áreas.

A reestruturação da assistência requer a reorganização do processo de trabalho em saúde para o atendimento das necessidades de saúde da população. Significa imprimir uma nova direcionalidade ao trabalho em saúde, na perspectiva do trabalho vivo, portanto com caráter dinâmico, criativo, não-estruturado e de alta possibilidade inventiva.

Reconhecer a saúde como qualidade de vida exige reconfigurações nas três esferas de governo. No âmbito federal e estadual, o grande desafio é mudar a estrutura organizativa setorizada, que tende a formular e implementar políticas de caráter isolado e fragmentado, para uma prática que possibilite operacionalizar políticas públicas intersetoriais capazes de impactar os determinantes e os condicionantes da saúde da população.

$\mathrm{Na}$ esfera municipal, a intersetorialidade precisa ser assumida como novo paradigma gerencial das cidades. Entretanto, soluções intersetoriais para os problemas da população requerem reformas profundas na esfera municipal, que permitam o planejamento regional e pactuado das intervenções públicas e que assegurem a participação dos cidadãos nas decisões que afetam sua qualidade de vida.

\section{REFERÊNCIAS}

1. Brasil. Constituição (1988). Constituição da República Federativa do Brasil. São Paulo, SP: Lemos e Cruz; 2004.

2. Ministério da Saúde. Relatório final da $8^{a}$ Conferência Nacional de Saúde - tema 1: saúde como direito. Brasília, DF: O Ministério; 1986.

3. Ministério da Saúde. As Cartas da promoção da saúde. Brasília, DF: O Ministério; 2002.
4. Chiesa AM. A promoção da saúde como eixo estruturante do programa de saúde da família. In: Anais do $1^{\circ}$ Seminário Estadual: o enfermeiro no programa de saúde da família; 2000 nov. 9-15; São Paulo, Brasil. São Paulo: Secretaria de Estado da Saúde; 2000.

5. Ministério da Saúde. Relatório: Consulta pública do perfil de competências do agente comunitário de saúde. 
Brasília, DF: O Ministério; 2004.

6. Mendes KDS, Silveira RCCP, Galvão CM. Revisão integrativa: método de pesquisa para a incorporação de evidências na saúde e na enfermagem. Texto \& Contexto Enferm [periódico na internet]. 2008 jun [acesso em 17 jun 2010];17(4):758-764. Disponível em: http://bases.bireme.br/cgi-bin/wxislind.exe/iah/online/? IsisScript = iah/ iah. $x i s \& s r c=$ google \&base $=$ LILACS\&lang $=p \&$ nextAction $=$ Ink\&exprSearch $=507765$ \&indexSearch $=$ ID

7. Cooper HM. Integrative research: a guide for literature reviews. 2nd ed. London: SAGE publication; 1989.

8. Organização Mundial de Saúde. Organization. Health Promotion Glossary. Geneva: WHO; 1998.

9. Zancan L. Cidades Saudáveis: a intersetorialidade como desafio para um novo modelo de gestão. In: Sperandio AMG, organizadora. O processo de construção da rede de municípios potencialmente saudáveis. Campinas: Ipes Editorial; 2003. p. 49-64.

10. Crevelim MA, Peduzzi M. Participação da comunidade na equipe de saúde da família: é possível estabelecer um projeto comum entre trabalhadores e usuários? Ciênc Saúde Coletiva [periódico na internet]. 2005 abr [acesso em 16 set 2012];10(2): 323-31. Disponível em: http://www. scielo.br/scielo.php? script $=$ sci_arttext\&pid $=$ S1413$-81232005000200010 \& \operatorname{lng}=$ pt.

11. Sales CM. Possibilidades e limites de execução das ações de promoção da saúde nos moldes da educação popular em saúde na estratégia saúde da família. Brasília. Tese [Doutorado em Ciências da Saúde] - Faculdade de Ciências da Saúde da UnB; 2009.

12. Iglesias A. Em nome da Promoção à Saúde: análise das ações em macrorregião do município de Vitória-ES. Vitória. Dissertação [Mestrado em Saúde Coletiva] - Universidade Federal do Espírito Santo; 2009.

13. Reis LB. Uma análise da dimensão ético política do trabalho de agentes comunitários de saúde do município de
Vitória. Vitória. Dissertação [Mestrado em Psicologia] Universidade Federal do Espírito Santo; 2005.

14. Oliveira VC. Comunicação, informação e participação popular nos Conselhos de Saúde. Saúde Soc 2004;13(2):56-69.

15. Labra ME. Política Nacional de Participação na Saúde: entre a utopia democrática do controle social e a práxis predatória do clientelismo empresarial. In: Fleury S, Lobato LVC, organizadoras. Participação, democracia e saúde. Rio de Janeiro: Cebes; 2009. p. 176- 203.

16. Silva JPV, Batistella C, Fonseca MLG. Problemas, necessidades e situação de saúde: uma revisão de abordagens para a reflexão e ação da equipe de saúde da família. In: Fonseca AF, organizadora. O território e o processo saúde-doença. Rio de Janeiro: EPSJV/Fiocruz; 2007. p. 159-76.

17. Vasconcelos EM. Redefinindo as práticas de Saúde a partir de experiências de Educação Popular nos serviços de saúde. Interface Comum Saúde Educ [periódico na internet]. 2001 Fev [acesso em 16 set 2012]; 5(8):121-126. Disponível em: http://www.scielo.br/scielo.php?script =sci arttext\&pid =S1414-32832001000100009\&lng = pt. http://dx.doi.org/10.1590/S1414-32832001000100009

18. Zinn GR. A dimensão educativa no trabalho dos agentes comunitários de saúde do programa de saúde da família. São Paulo. Dissertação [Mestrado em Ciências da Saúde ] - Pontifícia Universidade Católica de São Paulo; 2007.

19. Furlan PG. Veredas no território: análise da prática de Agentes Comunitários de Saúde. Campinas. Dissertação [Mestrado em Saúde Coletiva] - Universidade Estadual de Campinas; 2008.

20. Ceccim RB. Educação permanente em saúde: descentralização e disseminação de capacidade pedagógica na saúde. Ciênc Saúde Coletiva [periódico na internet]. 2005 Dec [acesso em 25 set 2012];10(4):975-986. Disponível em: http://www.scielo.br/scielo.php?script =sci arttext\&pid =S1413-81232005000400020\&Ing =en. 